\title{
Cutting the difficult papilla: Ancillary techniques in the performance of endoscopic sphincterotomy
}

\author{
Claude Liguory, MD, Jean François LeFebVRe, MD, Didier Bonnel, MD, Gary C Vitale, MD
}

\begin{abstract}
Of 1040 endoscopic sphincterotomies performed over a five year period, standard papillotomy was possible in $874(84 \%)$. In 166 cases $(16 \%)$ a difficult papilla was encountered requiring nonstandard techniques of precutting, transpapillary guided endoscopic sphincterotomy, transhepatic guided endoscopic sphincterotomy and percutaneous transhepatic sphincterotomy. The technique first attempted in these 166 cases was successfully completed in 154 (93\%). Among the 135 cases with intradiverticular papillas, successful papillotomy was achieved in $125(92.7 \%)$. Early complications of standard endoscopic sphincterotomy included bleeding, perforation, pancreatitis and cholangitis, comprising $4.3 \%$ of the 1040 sphincterotomies. There were five deaths (mortality rate $0.5 \%)$ and laparotomy was required in six patients $(0.6 \%)$. Conditions contributing to complications included an intradiverticular papilla and precutting. Evaluation of endoscopic sphincterotomy by transpapillary or transhepatic routes guided by guidewire or drain placement revealed complication rates of 6.6 and $10.6 \%$, respectively. Of the patients with histories of gastric resection and Billroth II anastomoses, standard sphincterotomy was possible in $15(55.5 \%)$; in two cases the papilla was unapproachable endoscopically, requiring use of percutaneous transhepatic sphincterotomy. The percutaneous transhepatic sphincterotomy without endoscopic control is felt to be a higher risk procedure and should be reserved for rare indications. Appropriate use of these techniques should allow performance of endoscopic sphincterotomy in almost all clinical settings. Can J Gastroenterol 1990;4(9):564-567
\end{abstract}

Key Words: Guided sphincterotomy, Precutting, Transhepatic sphincterotomy

\section{Section de la papille d'abord difficile: Techniques auxillaires dans la sphinctérotomie endoscopique}

RESUME: Sur les 1040 sphinctérotomies endoscopiques effectuées sur une période de cinq ans, la papillotomie standard était possible chez 874 (84\%). Dans 166 cas $(16 \%)$, la papille s'est avérée d'abord difficile, nécessitant le recours à des techniques non standard de précoupe, une sphinctérotomie guidée transpapillaire, une sphinctérotomie endoscopique guidée par voie transhépatique et une sphinctérotomie transhépatique percutanée. La technique tentée pour la

Clinique de L'Alma, Paris, France; and Department of Surgery, University of Louisville School of Medicine, Louisville, Kentucky, USA

Correspondence and reprints: Dr Claude Liguory, 7, Avenue de Breteville, 92200 Neuilly Sur Seine, France. Telephone (1) 47220440
$\mathrm{T}$ HE SUCCESS RATE OF ENDOSCOPIC sphincterotomy is dependent on a variety of factors. Most important among these are the experience of the endoscopist, the use of appropriate material (fibrescope and ancillary equipment) and the existence of anatomical problems.

Papillary variants such as a polypoid form, location at an unusual place in the duodenum and presence of a duodenal diverticulum are common problems. The papilla which is clearly located on the margin of or in a diverticulum may be difficult to access, but the simple presence of a diverticulum may change the orientation of the lower part of the common bile duct and thus make deep cannulation more difficult. Additional. ly, previous gastric surgery and reconstruction may make the papilla difficult or impossible to approach endoscopically. The present study focuses on these technically challenging papillas and identifies common features in series of patients presenting with each of these problems in an effort to facilitate mastery of the difficult sphincterotomy:

\section{PATIENTS AND METHOD}

A difficult papilla is defined as a normal or subnormal papilla through which it is impossible to introduce the papillotome deeply into the common bile duct for endoscopic sphinc. terotomy using the standard 'pull 
première fois dans ces 166 cas a été effectuée avec succès chez 154 (93\%). Parmi les 135 cas avec papille intradiverticulaire, une papillotomie a été réussie chez $125(92,7 \%)$. Les complications précoces de la sphinctérotomie endoscopique standard incluaient hémorragie, perforation, pancréatite et angiocholite, et touchaient $4,3 \%$ des 1040 sphinctérotomies. Il y a eu cinq décès, soit un taux de mortalité de $0,5 \%$, et une laparotomie s'est imposée dans six cas $(0,6 \%)$. Parmi les conditions particulières contribuant aux complications figuraient la présence d'une papille intradiverticulaire et le recours à une précoupe. L'évaluation de la sphinctérotomie endoscopique par voie transpapillaire ou transhépatique guidée sur fil ou sur drain révèle des complications chez 6,6 et 10,6\% des patients, respectivement. Parmi les sujets avec des antécédents de résection gastrique et d'anastomose de type Billroth II, la sphinctérotomie standard était possible dans $15(55,5 \%)$ cas; dans deux cas, la papille était inabordable par endoscopie, nécessitant le recours à la sphinctérotomie transhépatique percutanée. On estime que la sphinctérotomie transhépatique percutanée sans contrôle endoscopique comporte des risques plus élevés et qu'elle devrait être réservée aux indications rares. L'utilisation appropriée de ces techniques devrait rendre la sphinctérotomie endoscopique possible dans presque toutes les situations cliniques.

technique'. Patients with previous gastric resection and Billroth II reconstruction have been included, while patients with periampullary tumours have not. Thus, all patients in this study underwent sphincterotomy for the indications of common bile duct lithiasis or benign stricture.

From January 1985 through May 1989, 1040 endoscopic sphincterotomies were performed at the Clinique de l'Alma. There were 49 patients (4.7\%) who had been referred after an unsuccessful attempt at endoscopic sphincterotomy at another centre. The papilla was located at the inner edge or inaduodenal diverticulum in 135 cases. In 27 patients there was a history of previous gastric resection with Billroth II anastomosis. A review of the 1040 consecutive cases revealed that the difficult papilla was encountered in 166 (16\%). Four different techniques were used to successfully cut the difficult papilla, depending on the anatomy, as follows.

Precutting: The precutting technique allows selective bile duct cannulation after a small incision upward on the papillary orifice or on the bulging infundibulum is made. A diathermy blade is used through a standard catheter to perform this technique.

Transpapillary guided endoscopic sphincterotomy: Introduction of a guidewire into the bile duct via the endoscopic route allows subsequent introduction of a special papillotome over the guidewire. The sphincterotomy is then performed after removal of the guidewire.

Transhepatic guided endoscopic sphincterotomy: If a guidewire cannot be introduced into the bile duct via the endoscopic approach, a percutaneous transhepatic approach can be used for insertion of an internal-external drain across the papilla, followed by a guided sphincterotomy under endoscopic control. The drain creates an artificially wide open papilla in this case. The tip of the papillotome is inserted in the open end of the drain and pushed into the papilla as the drain is carefully withdrawn. The sphincterotome is then in position for sphincterotomy. Variations of this technique include passage of the sphincterotome alongside the drain into the papilla, or use of the diathermy blade to cut the papilla, over the drain in the direction of the infundibulum. The sphincterotome can then be introduced into the bile duct to complete the sphincterotomy. Alternatively, a guidewire alone may be placed via the transhepatic route with endoscopic insertion of the sphincterotome over the guidewire into the papilla. This latter technique obviates the need for dilation of the transhepatic tract for drain insertion.

Percutaneous transhepatic sphincterotomy: This technique is reserved for the rare case of the endoscopically unapproachable papilla. A guidewire is first placed transhepatically across the papilla. A special papillotome is then inserted over the guidewire to perform the sphincterotomy transhepatically under fluoroscopic control. The procedure is performed with visualization of the common bile duct throughout by injection of contrast media through the papillotome. One must place the cutting wire at the choledochoduodenal junction under fluoroscopic control.

\section{RESULTS}

Standard papillotomy was possible and successfully completed in 874 patients (84\%). Of the 166 cases $(16 \%)$ with a difficult papilla, the technique of first attempt was precutting in 118 cases, transpapillary guided endoscopic sphincterotomy in 30, transhepatic guided endoscopic sphincterotomy in 16 and percutaneous transhepatic sphincterotomy in two. Both patients in this last group had undergone gastric resection with Billroth $\mathrm{II}$ anastomoses. Additionally, there were 12 cases of precutting failures; transhepatic guided endoscopic sphincterotomy was the secondary procedure of choice in these cases bringing the total to 42 for this technique.

The technique first attempted could not be completed in 12 of the 166 difficult papilla cases $(7 \%)$. In these 12 failures, all precutting, a transhepatic guided endoscopic sphincterotomy was used to successfully complete the procedure. Table 1 delineates distribution of techniques and success rate. Among the 135 cases with intradiverticular papillas, a successful papillotomy was achieved in 125 (92.7\%).

Early complications of standard endoscopic sphincterotomy included bleeding, perforation, pancreatitis and cholangitis. There were $45(4.3 \%) \mathrm{com}$ plications in the 1040 sphincterotomies (Table 2). There were five deaths giving a mortality rate of $0.5 \%$. Laparotomy was required in six cases $(0.6 \%)$. Bleeding $(1.7 \%)$ and perforation $(1.1 \%)$ were the most common complications, comprising all patients requiring laparotomy and all but one of the deaths. There was one death attributed to cholangitis.

Special conditions contributing to complications included an intradiver- 
TABLE 1

Technique of first attempt of endoscopic sphincterotomies

\begin{tabular}{lccc}
\hline & \multicolumn{2}{c}{ Cases } & \\
Method & n & $\%$ & Success rate (\%) \\
\hline Standard sphincterotomy & 874 & 84 & 100 \\
Precutting & 118 & 11.4 & 92 \\
Endoscopic sphincterotomy & & & \\
Transpapillary guided & 30 & 2.9 & 100 \\
Transhepatic guided & 16 & 1.5 & 100 \\
Percutaneous transhepatic sphincterotomy & 2 & 0.2 & 100 \\
\hline
\end{tabular}

nNumber of cases

\section{TABLE 2}

Early complications of 1040 endoscopic sphincterotomies (common bile duct lithiasis)

\begin{tabular}{lrccc} 
Complication & \multicolumn{2}{c}{ Cases } & & \\
Bleeding & $\mathbf{n}$ & $\%$ & Laparotomy & Mortality \\
Perforation & 18 & 1.7 & 2 & 2 \\
Pancreatitis & 12 & 1.1 & 3 & 2 \\
Cholangitis & 10 & 1.0 & 0 & - \\
Bleeding + perforation & 4 & 0.4 & 0 & 1 \\
Total & 1 & 0.1 & 1 & - \\
n Number of cases & 45 & 4.3 & $6(0.57)$ & $5(0.5)$ \\
\hline
\end{tabular}

ticular papilla and precutting. Of the 18 cases with hemorrhage, four were in patients having an intradiverticular papilla and three in patients having undergone precutting. Of the 12 cases with perforation, there were two and four patients with intradiverticular papillas and precutting, respectively. This yields 3\% hemorrhage and $1.5 \%$ perforation rates for sphincterotomy in the presence of an intradiverticular papilla and $2.5 \%$ hemorrhage and $3.4 \%$ perforation rates in patients undergoing precutting.

Techniques used in the approach to patients with previous gastric resection and Billroth II anastomoses are noted in Table 3. The papilla could not be visualized with standard duodenoscopy in two patients; these two went on to undergo percutaneous transhepatic sphincterotomy. Standard sphincterotomy was possible in 15 of 27 patients $(55.5 \%)$. In the two cases of unapproachable papillas the papillotomy was performed without endoscopic control, and there was one case of massive bleeding which was managed conservatively using lavage through the percutaneous drain and blood transfusions.

Evaluation of endoscopic sphincterotomy guided by transpapillary or transhepatic routes revealed complication rates of 6.6 and $10.6 \%$, respectively. As expected, the transhepatic route carried a higher risk than the $4 \%$ complication rate found following standard sphincterotomy. The higher rate of complications with the percutaneotis approach is related to transhepatic drain placement. The complication rate of endoscopic sphincterotomy after precutting was $11.8 \%$, and evaluation of these cases revealed that complication was related to local anatomy, being lower in cases with a bulging, well defined infundibulum.

\section{DISCUSSION}

Anazawa et al (1) first extracted a stone across the papilla using a biopsy forceps in 1972. The first work on endoscopic sphincterotomy for calculi of the common bile duct was performed simultaneously in Germany (2) and Japan (3) in 1973 and in France (4) in 1974. Since then thousands of sphincterotomies have been practised throughout the world, and this endoscopic surgical technique certainly represents a major therapeutic advance in the treatment of obstructive disease of the biliary tract.

Endoscopic papillotomy is now possible in nearly all cases using a variety
TABLE 3

Endoscopic sphincterotomy and Billroth II anastomosis $(n=27)$

\begin{tabular}{lrr}
\hline & $\mathbf{n}$ & $\%$ \\
\hline Successful & & \\
Standard sphincterotomy & 15 & 55.5 \\
Infundibulotomy & 7 & 26.0 \\
Total & 22 & 81.5 \\
Unsuccessful & & \\
$\quad$ Papilla not visualized & 2 & 7.4 \\
$\begin{array}{l}\text { Failure to introduce } \\
\quad \text { sphincterotome }\end{array}$ & 3 & 11.1 \\
$\quad$ & 5 & 18.5 \\
\hline Total & & \\
\hline Number of cases & &
\end{tabular}

of combined endoscopic and transhepatic approaches. The choice of technique depends on papillary anatomy. The papillary projection has a variable form, usually hemispheric with con centric grooves, but it is occasionally multilobular and rarely flat. These variations can make cannulation difficult and may limit the application of ancillary techniques used in cutting the difficult papilla. At the tip, the papillany orifice also has a variable appearance, being villous in $52 \%$, granular in $15 \%$ irregular in $13 \%$, vertically opening in $11 \%$, and circular and fixed in $3 \%(5)$. In rare cases $(0.56 \%)$ there exist two separate papillas for the biliary and pancreatic ducts (6). The superior orifice gives access to the bile duct and the inferior gives access to the pancreatic duct. From a practical point of view, papillary anatomy is quite vari. able and there are really no two papillas exactly alike.

The appearance of the infundibulum is also quite variable and may vary depending on clinical presentation. For example, the infundibulum is quite pro. minent and firm when a common bile duct stone is trapped within the papilla. Additionally, it can be the location for choledochoduodenal fistulas and have the appearance of either a true orifice or a simple mucosal erosion (7); the infun. dibulum may be absent. The distance between the papillary orifice and the junction of the common bile duct and duodenum varies between 15 and $21 \mathrm{~mm}$ and can be longer in cases of lithiasis of the common bile duct $(7,8)$.

For the standard sphincterotomy. the authors prefer the proximal sphincterotome with the cutting wire placed 3 to $4 \mathrm{~cm}$ from the distal tip. This 
has two advantages: the introduction of 5 to $6 \mathrm{~cm}$ of sphincterotome into the papilla serves to stabilize the instrument and allows graded movements to obtain the best possible position prior to sectioning of the papilla; and the risk of expulsion of the sphincterotome during sphincterotomy is avoided $(9,10)$. In case of failure, the distal sphincterotome is used with the cutting wire positioned at the end $(11,12)$.

The present authors initially attempt guidewire placement across the papilla endoscopically in the event of failure of selective cannulation of the bile duct with standard methods. If successful, a guided sphincterotomy can be performed with a minimally higher complication rate (6.6 versus $4 \%$ for standard techniques). In the event of failure to pass a guidewire into the sphincter orifice, precutting is attempted if there is a well defined and

\section{REFERENCES}

1. Anazawa W, Takagi K, Kuno K. Endoscopic removal of gallstone impacted at the major papilla: A case report. Stom Intest 1972;7:64.

2. Classen M, Demling L. Endoscopische sphinkterotomie der papilla Vateri und stein extraktion aus dem ductus choledocus. Dtsch Med Wochenschr 1974;99:496-7.

3. Kawai K, Akasaka Y, Hashimoto Y, Nasajima M. Preliminary report on endoscopical papillotomy. J Ky Pref Med Univ 1973;82:353-5.

4. Liguory C, Coffin JC, Hoeller A, Chavy A. Lithiase de la voie biliare principale: Traitement par voie endoscopique. Nouv Presse Med 1975;4:20.

5. Oi l. Insertion of the duodenoscope and observation of the duodenal papilla in endoscopic retrograde cholangiography. In: Takemoto T, Kasugai T, eds. Endoscopic Retrograde Cholangiography. New York: Igaku Shoin, 1979:13-22.

6. Ohto M, Ono T, Tsuchiya Y, Saisho H. Hypotonic duodenography combined with PTC. In: Cholangiography and Pancreatography. Tokyo-New York: Igaku Shoin, 1978:98-121.

7. Ikeda S, Okada Y. Classification of choledocho-duodenal fistulas diagnosed by duodenal fiberoscopy and its etiological significance.

Gastroenterology 1975;69:130-7.

8. Barraya L, Pujol-Soler R, Yvergneaux bulging infundibulum.

This technique can be performed with a standard sphincterotome or with a special one with a very short $(1 \mathrm{~cm})$ cutting wire exiting the distal end of the catheter $(13,14)$. The authors prefer to use the diathermic wire with a diameter of $0.2 \mathrm{~mm}$ exteriorized 3 to $5 \mathrm{~mm}$ from the end of the catheter (9). The precutting method is not used if the papilla is planar or excessively hidden in duodenal folds. Additionally, precutting is only rarely used in cases of papillary association with duodenal diverticula, as this anatomic association significantly increases complications, notably perforation. Transhepatic guided endoscopic sphincterotomy is reserved for very select cases with good indications for the procedure and failure of standard methods - precutting (if anatomically appropriate) and transpapillary guided techniques (15-18). It is also used as the

JP. La région oddienne. Anatomie millimétrique. Presse Med 1971;79:2527-34.

9. Liguory C, Sahel J. Endoscopie Digestive Pratique. Padova: Piccin Nuova Libraria, 1988:237-41.

10. Cremer M, Gulbis A, Toussaint J, DeToeuf J, VanLaethem A, Hermanus A. Technique of endoscopic papillotomy. In: Delmont J, ed. The Sphincter of Oddi. Basel: Karger, 1977:219-27.

11. Coffin JC, Liguory C. Les sphinctérotomes. Endosc Digest 1978;3:191-9.

12. Dunham FM, Deltenre K, Jeanmart J, Toussaint J, Cremer M. Special catheters for ERCP. Endoscopy 1981;2:55-8.

13. Siegel JH. Precut papillotomy: A method to improve success of ERCP and papillotomy. Endoscopy 1980;12:130-3.

14. Huibregtse K, Katon RM, Tytgat GNS. Precut papillotomy via fine needle knife papillotome: A safe and effective technique. Gastrointest Endosc 1986;32:403-5.

15. Passi RB, Rankin RN. The transhepatic approach to a failed endoscopic sphincterotomy. Gastrointest Endosc 1986;32:211-25.

16. Shorvon PS, Cotton PB, Mason RR, Siegel JH, Hatfield ARW. Percutaneous transhepatic assistance for duodenoscopic sphincterotomy. Gut 1985;26:2373-6. procedure of second choice if the infundibulum is not clearly defined or not visible.

Percutaneous transhepatic sphincterotomy is considered dangerous and should be pursued only in very select cases in which sphincterotomy is mandatory and the papilla is truly unapproachable by all standard techniques $(19,20)$. Usually, the papilla is not endoscopically visible due to previous surgical intervention such as gastrectomy with Billroth II or Roux-en-Y reconstruction (21-23).

In summary, a careful approach to the difficult papilla based on solid anatomic understanding with appropriate ancillary equipment and interventional radiological help should improve the interventional biliary endoscopist's ability to perform successfully and safely an endoscopic sphincterotomy in almost all clinical settings.

17. Cotton PB, Mason RR. Combined duodenoscopic and transhepatic approach to stenosis of the papilla of Vater. Br J Radiol 1981;54:678-9.

18. Hatfield ARW, Murray RS, LennardJonnes JE. Peri-ampullary diverticula and common bile duct calculi: A combined transhepatic and endoscopic technique for difficult cases. Gut 1982;23:A389. (Abst)

19. Wurbs D, Dammermann R, Ossenberg FW, Classen M. Descending sphincterotomy of the papilla of Vater through the $T$ drain under endoscopic view. Endoscopy 1978;10:199-203.

20. Wurbs D, Hagenmuller F, Classen M. Descending sphincterotomy of the papilla of Vater through a choledochoduodenostomy under endoscopic view. Another variant of endoscopic papillotomy (EPT). Endoscopy 1980;12:38-40.

21. Rosseland AR, Osnes M, Kruser A. Endoscopic sphincterotomy (EST) in patients with Billroth II gastrectomy. Endoscopy 1981;13:19-24.

22. Safrany L, Neuhaus B, Portocarrero G, Krause S. Endoscopic sphincterotomy in patients with Billroth II gastrectomy. Endoscopy 1980;12:16-22.

23. Siegel JF, Yatto RP. ERCP and endoscopic papillotomy in patients with a Billroth II gastrectomy. Report of a method. Gastrointest Endosc 1983;29:99. 


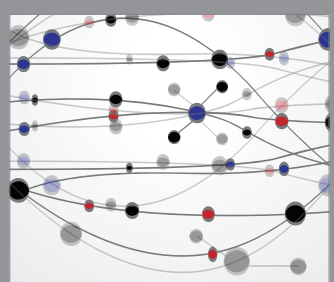

The Scientific World Journal
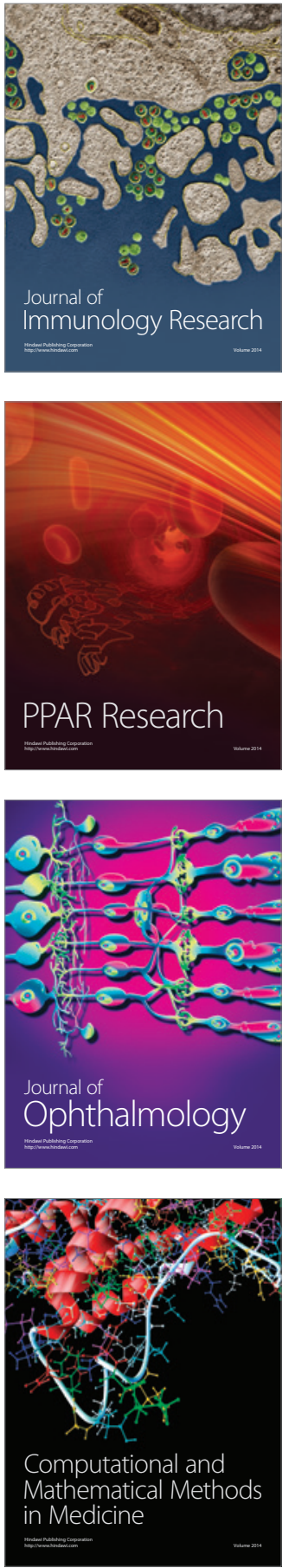

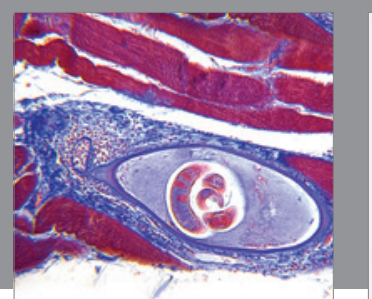

Gastroenterology Research and Practice

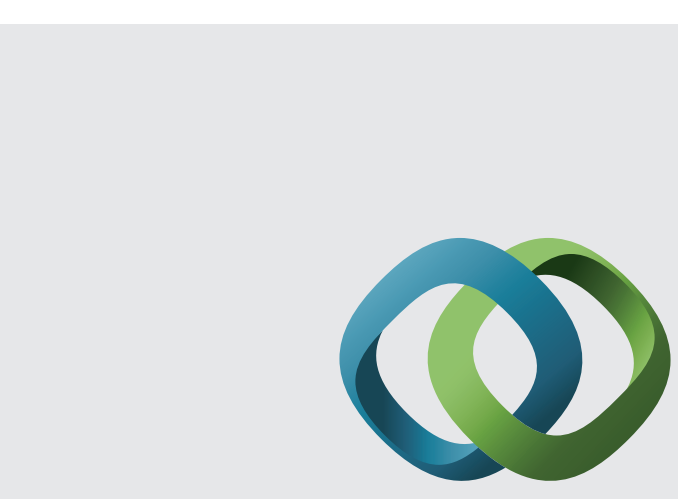

\section{Hindawi}

Submit your manuscripts at

http://www.hindawi.com
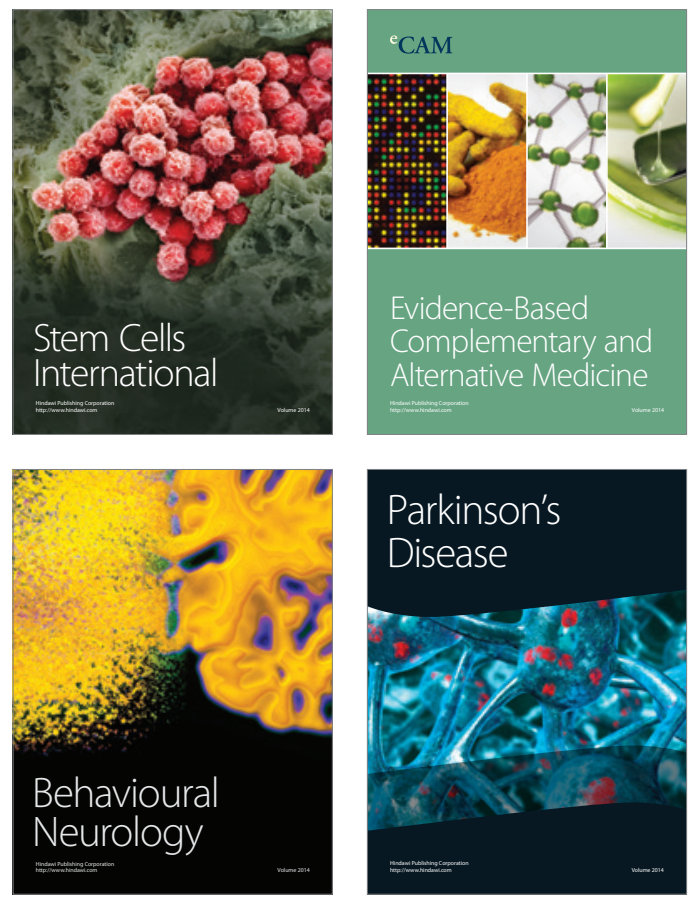
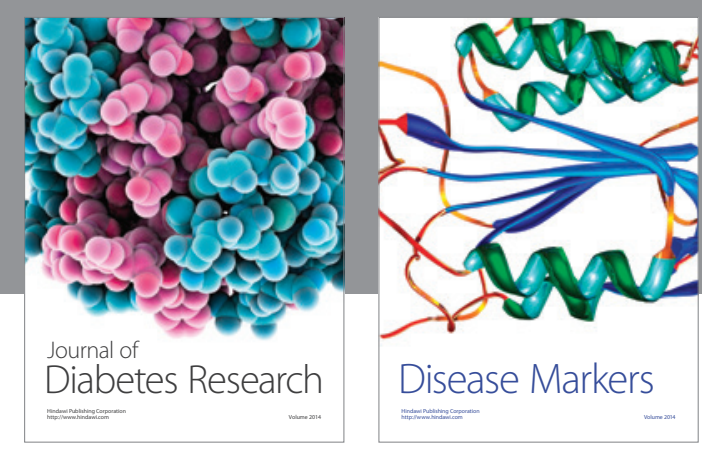

Disease Markers
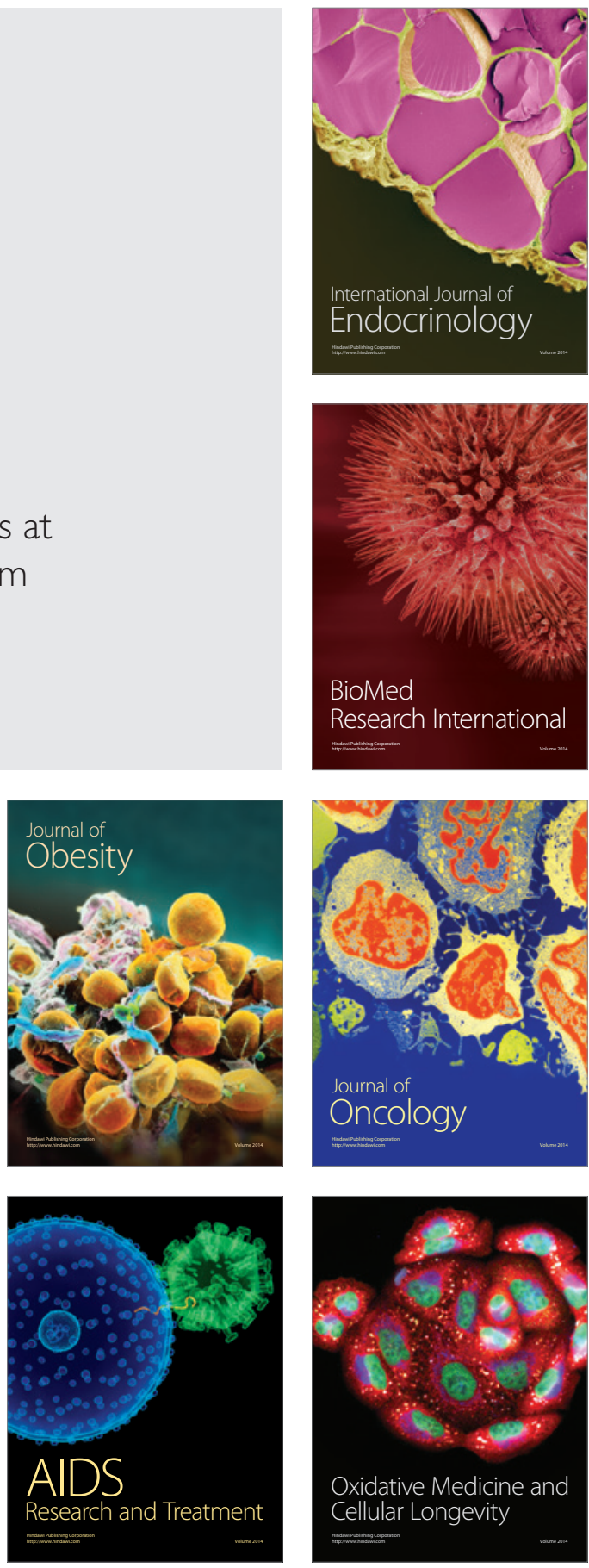